\title{
Form and Content in Hawthorne’s The Scarlet Letter: A Stylistic Study of Dimmesdale’s Narrative Sentences
}

\author{
Shaimaa Mohamed Mahmoud Helal \\ Newcastle University, Newcastle, UK
}

\begin{abstract}
Hawthorne's The Scarlet Letter (1850) is a unique work. Since the time of its publication, various papers have been published that deal with various aspects of Dimmesdale's character from a literary point of view. The linguistic studies are almost lacking, although of the richness of Hawthorne's language employed in the revelation of Dimmesdale's character. From this point, emerges the importance of this stylistic study that sheds much light on the relationship between the diverse syntactic structures employed by Hawthorne in Dimmesdale's character to create certain effects on the reader, and the revelation of the character as a whole. This study analyzes the basic stylistic features of Dimmesdale's sentences via diverse grammatical structures, and appreciates the array of the writer's grammatical choices that lead to the specific structure and eventually revelation of the character. The concentration will be on the writer's use of parenthetical constituents as a stylistic feature in Dimmesdale's narrative sentences. The parsing of the sentences that reveal Dimmesdale's character follows the system used in Leech, Deuchar, and Hoogenraad (1982). This system is chosen to represent the framework of the grammatical analysis of the paper, because it provides not only a simplified method of analysis, but also a concise one. Breaking Dimmesdale's narrative sentences into its grammatical components enable us to analyze each component alone, on its own terms, and understand how it fits together with other components. This increases our appreciation of the text as a whole (Thornborrow \& Wareing, 1998). This paper reaches the conclusion that Hawthorne successfully employs different stylistic features, particularly the use of parenthetical structure, to reveal various aspects of Dimmesdale such as hypocrisy, suffering, and agony. These features are embedding (68\%), retaining the most complex structure to the end of the sentence (47\%), fronting of an element (39\%), using periodic sentences (26\%), using parenthetical constituent (30\%), distancing structurally related items (20\%), and other features that will be discussed in details in the paper.
\end{abstract}

Keywords: parenthetical constituents, stylistics analysis, form and content

\section{Introduction}

This paper sheds light on the relationship between the various stylistic features of Dimmesdale's narrative sentences, particularly the use of parenthetical constituents, and the revelation of Dimondale's character. So, it examines the relationship between form (represented by syntactic analysis of sentences) and content (represented by the meaning of certain arrangement of syntactic elements which chosen by the writer from the repertoire of

Shaimaa Mohamed Mahmoud Helal, Ph.D., School of English Literature, Language \& Linguistics, Newcastle University. 
language available to him). It answers the questions: Why Hawthorne chooses certain structures to narrative sentences that are devoted to Dimmesdale? Does he want to convey certain meanings that cannot be conveyed by another structure? From the study, it turns out that Hawthorne successfully manages to structure the narrative sentences of Dimmesdale's character in a way that create certain effects on the reader, which if altered or omitted that will change its designated effect on the reader.

\section{Stylistics and the Study of Literary Language}

Stylistics is a major discipline that brings together and unites both of linguistics and literary criticism. It does not use the categories of these two disciplines; on the contrary, it uses special categories, tools, and procedures for achieving its purpose. Therefore; it is an independent discipline and its method is "retrievable" (Simpson, 2004, p. 6). Here the word "retrievable" suggests that the stylistic analysis is organized through explicit terms and criteria, the meanings of which are agreed upon by all stylisticians. The same view is reflected by Ullmann (1973) when he stated that: "Stylistics is not a mere branch of linguistics but a parallel discipline which investigates the same phenomena from its own point of view" (p. 41).

Literature is regarded as the art which uses language as its medium as well as means of expression. That is why the study of its language reflects the interest of certain unique types of "rearrangement" and "modification" of the elements and rules of the language (Guirad, 1971, p. 20). For the previous reasons, in the study of literary language, the employment of linguistics, as a discipline which attempts to analyze language from the point of view of its internal structure, turns out to be of limited use. Criticism alone cannot handle the problems of the language used by literary writers, particularly in the area of sentences' order, grammar, and the use of different structural features.

Stylistics is the only discipline that relates linguistic description and critical appreciation. Stylistics is "a meeting-ground of linguistics and literary studies” (Leech, 1969, p. 2). As asserted in the words of Carter (1989): "Stylistics is essentially a bridge discipline between linguistics and literature" (p. 161). According to Widdowson (1975): "Stylistics occupies the middle ground between linguistics and literary criticism and its function is to mediate between the two" (p. 117). As a consequence, it is the discipline that helps a great deal in revealing the secrets of literary language. By focusing on the language of literary text, stylistics also helps in the interpretation of the meaning of literary text. Leech (1970) rightly assumed that: "Linguistic description and critical interpretation” are "distinct and complementary ways of explaining a literary text” (p. 120).

\section{Form and Content}

\section{Introduction}

Language is not merely words but it is a complex system that requires the learning of certain rules which construct these words to form meaningful sentences. In Jespersen's (1925) view, “to learn a language it is not enough to know so many words", but "they must be connected according to the particular laws of the particular language” (p. 128). So here appears the importance as well as the significance of studying the relationship between structure and meaning, i.e., form and content. By form we mean structure, by structure we refer to grammar, and by grammar we intend to refer to "the rules of constructing sentences out of words" (Leech et al., 1982, p. xii). According to Mills (1996): “The term grammar is frequently used to describe our knowledge of the 
separate parts of a sentence" (p. 7). To Thornborrow and Wareing (1998), grammar is "the knowledge that every speaker has of the language that they speak" (p. 52).

\section{Grammar and Its Relation to Meaning}

The linguist who is interested in studying the grammatical aspects of text, is interested in studying the meaning of the text as well, i.e., its semantics (Robins, 1971, p. 259). So this reflects the mutual relationship between grammar and meaning. Nowottny (1984) argued that: “... Of all the elements necessary to make an utterance meaningful, the most powerful is syntax [grammar], controlling as it does the order in which impressions are received and conveying the mental relations 'behind' sequences of words” (p. 71). So, here, one can assume that syntax plays an essential role in conveying the meaning of the sentences. The same view is reflected by Wardhaugh's (1977) words: “... The deep syntactic structure of a sentence and the meanings of the words used in that structure represent the total meaning of the sentence” (p. 165). Most scholars agreed that analyzing grammar is important not only for our understanding of language but also for recognizing and studying “different kinds of linguistic variation” (McEnery \& Wilson, 2001, p. 110).

\section{Stylistics, Grammar, and Effective Communication}

The aim of stylistics is to examine the structure of literary text in order to describe the different stylistic features employed by its writer as well as the effects produced by the choice of such stylistic features and hence, more importantly, to reach the interpretation of the text as a whole. As Alderson and Short (1989) declared: "Stylistic analysis is intended to help determine interpretation through the examination of what a text contains, by describing the linguistic devices an author has used, and the effects produced by such devices” (p. 72). Therefore, the stylistic analysis' concentration on what is written, i.e., on the literary text itself leads, rightly, to the interpretation of the meaning of the literary text and hence the literary work as a whole. For example, the focus on what Nathanial Hawthorne wrote about Arthur Dimmesdale, the minister in The Scarlet Letter (1850), leads to the extraction of certain stylistic features that are closely connected with the portrayal of Dimmesdale's tortured soul and hence the interpretation of every thing related to him: his acts, his words, his motifs, and so on. Relying on the text in the process of interpretation leads to correct interpretation since this achieves the faithfulness to the literary text. As Mayhead (1969) assumed: "Only through attention to what is written, therefore, can we hope to arrive at the author's whole meaning” (p. 91). The interpretation of the literary meaning leads to literary appreciation in which syntax plays an essential role since, according to Halliday (1973), it works "to weave into a single fabric the different threads of meaning” (p. 119).

In studying grammar, one can say that the parts of the sentences: the subject, the predicator, the object, the complement, and the adverb can be viewed as items which can be manipulated within the structure of the sentences for different kinds of prominence, therefore; Quirk and Greenbaum (1973) asserted that: "Studying these aspects of linguistic structure makes one aware of language as a sequentially organized communication system, in which judicious ordering and placing of emphasis may be important for the proper understanding of the message and its implications” (p. 406). For creating effective communication, the writer can arrange and present the meanings of his sentences in various ways: by cutting up his message of the sentence into individual piece of information, and by giving his ideas the right emphasis as well as putting them in the right order (Leech \& Svartivk, 1975, p. 169). The same view was asserted by Thornborrow and Wareing (1998): “In 
literary language particularly, the structures of grammar can be 'stretched' or 'disrupted' in various ways to produce different effects” (p. 53). That is why Hawthorne prefers certain grammatical structures to others. They allow him to create effective communication and to reflect the specific meaning that he wants to convey to his readers. The interpretation of Dimmesdale's character in The Scarlet Letter and the message that Hawthorne wants to convey to the readers can only be achieved by the close analysis of the grammatical structures of the work and this is the aim of this paper.

\section{Stylistic Study of Dimmesdale's Character.}

\section{Hypothesis}

The close grammatical analysis of Hawthorne's sentences that are related to Dimmesdale leads to the recognition of the writer's divers grammatical structures, and hence to the extraction of his stylistic features which, in turn, illuminate the reader's mind and, as a result, provide him/her with deeper level of understanding the literary work and this drives to further interpretation of the literary work's meaning and, finally, appreciation of its writer's style in reflecting the various aspects of the character under study, i.e., Arthur Dimmesdale.

The present paper attempts to answer the following questions: (1) How Hawthorne's sentences are constructed in narrative sentences that are related to Dimmesdale's character?; (2) What are the types of sentences that Hawthorne uses in revealing Dimmesdale's character in The Scarlet Letter?; (3) Does he favor the use of certain type in his sentences? i.e., does he favor to use complex sentence-type to simple or compound one?; (4) Which type of sentences that Hawthorne favor to use in the sentences of Dimmesdale's character?; (5) Do sentences on the whole have a simpler or a complex structure?; (6) How complex are the sentences?; (7) What kinds of complexity are found?; (8) Does complexity vary notably from one sentence to another?; (9) Is complexity mainly due to: (a) coordination, (b) subordination?; (10) In what parts of the sentence does complexity tend to occur? For instance, is there any notable occurrence of anticipatory constituents (e.g., of complex subjects preceding the verbs, of dependent clauses preceding the subject of a main clause)?; (11) Does the writer tend to use loose sentence structure or periodic sentence structure in his complex sentences of Dimmesdale? Which one does he prefer and why?; (12) Are there marked uses of coordination or subordination, of linked or unlinked coordination?; (13) What types of dependent clause are favored: relative clauses, adverbial clauses, and different types of nominal clauses (that-clauses, wh-clauses, etc.)?; (14) Are non-finite clauses commonly used, and if so, of what type are they (infinitive clauses (CLi), -ING clauses (Cling), and EN-clauses (CLen))?; (15) Are there any unusual orderings (initial adverbials, fronting of object or complement)?; (16) Do special kinds of clause construction occur (such as those with preparatory it or there)?; (17) What are the main stylistic features that occur in Hawthorne's Dimmesdale character?; (18) Can these stylistic features be related to the interpretation to the character?; (19) Does the form serve to reinforce the meaning?; and (20) Is the psychological/physical suffering reflected in grammar?.

\section{Statistics}

These and various other questions will hopefully be explicitly or implicitly answered in the present paper. For this purpose, an extensive statistical account of Hawthorne's various stylistic features employed in Dimmesdale's narrative sentences carried out. The sample analysis represents the narrative sentences of Dimmesdale in 10 chapters of the novel. The total number is 274 sentences. These sentences are syntactically 
analyzed according to the system of parsing used in Leech et al. (1982). Then various stylistic features are extracted from the parsing.

Table 1 shows the proportions of different types of sentences used in 274 narrative sentences of Dimmesdale's character.

Table 1

Sentences' Types of Dimmesdale's 274 Narrative Sentences

\begin{tabular}{lcr}
\hline Dimmesdale's 274 narrative sentences & & \\
\hline Sentences types & Total & $\%$ \\
Complex sentences & 183 & 72.4409 \\
Compound sentences & 13 & 8.6614 \\
Simple sentences & 70 & 18.8976 \\
p-less structure(sentence fragment) & 8 & 2.9197 \\
\hline Total & 274 & \\
\hline
\end{tabular}

The majority of Hawthorne's sentences that are devoted to the revelation of Dimmesdale's character tend to have the type of complex sentence. From the statistics, this type, complex sentence-type, represents the highest percentage 72.4409. As a result, one can assume that Hawthorne favors the use of complex sentence-type in dealing with Dimmesdale's character.

Hawthorne prefers this type, complex sentence-type, to other types, because it copes up with the general thread of suffering, agony, and torture of the minister due to his sin of adultery as well as with the design of the novel which deals with various complex themes such as death, repentance, sin, appearance, hypocrisy, and alienation. The expression of all these intricate, deep, and complex themes requires, in the author's opinion, a type of sentences which allows the use of subordination that helps in dealing with more than one idea as well as subordinating one clause or more of less importance to another. That type is complex sentence-type. One should say that the use of complex sentences can be regarded as a reference, working along with other factors, that reflects the complexity of Hawthorne's style employed in Dimmesdale's narrative sentences, a style which represents the complexity of Hawthorne's language, and hence leads to the overall difficulty of the language used in The Scarlet letter.

Table 2 shows the stylistic features employed by Hawthorne in 274 narrative sentences of Dimmesdale's character in The Scarlet Letter. The features are arranged in the table in descending order.

One notices that in dealing with Dimmesdale's sentences, Hawthorne is fond of using the stylistic feature of subordination. It represents the highest proportion of other stylistic features. From 274 narrative sentences, 187 include the stylistic feature of embedding with $68.248 \%$. From Table 2, one also finds that the stylistic feature of using the NP phrase in apposition, on the contrary to the stylistic feature of embedding (subordination), represents the lowest proportion of the stylistic features used in Dimmesdale's sentences. It represents five cases from 274 with $1.824 \%$. Since all the features are arranged in the table in descending order, so this means that the frequency of occurrence increases as one goes up in the table, and this, in turn, means that there are features which tend to have high proportions and other that tend to have low proportions. Therefore, one should divide the stylistic features into two groups: group one and group two. Group one reflects the stylistic features which are used with high frequency of occurrence, consequently they are Hawthorne's widely used features in 
Dimmesdale's sentences, while group two represents the stylistic features which have low proportions, hence, they are not used so much by Hawthorne. From Table 2, the stylistic features which represent group one, in descending order, start with embedding and end with use of parenthetical constituent, while the stylistic features of group two start with the use of periodic sentences, and end with use of NP phrase in apposition.

Table 2

Stylistics Features of Dimmesdale's 274 Narrative Sentences

\begin{tabular}{lrl}
\hline Stylistics features & $f$. & $\%$ \\
\hline Embedding (the process itself) & 187 & 68.248 \\
Retaining the most complex structure to the end of the sentence & 131 & 47.810 \\
Fronting (subject, object, or complement) & 108 & 39.416 \\
Delaying (any structure) & 103 & 37.591 \\
Post modification of the head of the s., o., or c. (any structure) & 97 & 35.401 \\
Use of parenthetical constituent & 83 & 30.291 \\
Periodic sentences & 73 & 26.642 \\
Distancing structurally related items & 55 & 20.072 \\
Split constituent & 43 & 15.693 \\
Subject-verb inversion & 24 & 8.759 \\
Enclosure or confinement & 10 & 3.649 \\
Postponement of post modifier & 7 & 2.554 \\
Extraposition (of clausal subject) & 6 & 2.189 \\
Use of NP phrase in apposition & 5 & 1.824 \\
\hline
\end{tabular}

Note. $f$. = frequency of occurrence.

\section{Result of the Research}

Hawthorne's choice of language employed in Dimmesdale's character in The Scarlet Letter tends to be complex. There are many sources of this complexity. The writer's favor of using complex sentence-type is one of the reasons of the complexity of his style, because, the complex sentence, as Crystal (2003) assumed: "consists of a main clause and at least one subordinate clause” (p. 90). Consequently, each complex sentence contains at least, if not more, one subordinate clause which in turn plays an essential role in complicating the structure of the sentence, because, "it characteristically function[s] as dependent within some larger construction" (Huddleston \& Pullum, 2005, p. 174). So the understanding of its meaning depends upon understanding the meaning of the "larger construction", i.e., the main clause, of which it is part of. Since Hawthorne constructs his complex sentence with more than one subordinate clause, the total numbers of subordinate clauses are more than the total number of complex sentences. In other words, each complex sentence does not represent only one process of embedding represented by one subordinate clause, but there are more than one subordinate clause and that means that there are huge numbers of embeddings. The big number of embeddings is the second reason of the source of the complexity of style in constructing Dimmesdale's sentences. One should say here that embedding does not only mean embedding of a clause inside a phrase or inside another clause, the two types which counted, implicitly, in the statistics of Hawthorne's style, but there are other types such as "phrase-within-phrase((Ph))", “word-within-word”, “phrase-within-word”, and “clause-within-word” (leech et al., 1982, pp. 103-104).

Hawthorne's complexity of structure is mainly due to subordination which, from the statistics, tends to occur at the end of the syntactic structure of the majority of the narrative sentences. When Hawthorne makes 
complexity of structure appear at the end of the sentence rather than at the beginning, he reflects his concern with making complexity of structure appears in right-branching instead of left-branching. Leech et al. (1982, p. 138) argued that complexity in right-branching is easier in understanding than complexity in left-branching. Consequently, one can say that Hawthorne's language in reflecting Dimmesdale's character is complex, but the writer tries to make things easy for the reader by making subordination appear at the right-branching of the syntactic structure of the sentence instead of the left-branching. Also, this reflects his favor of loose sentence structure to periodic sentence structure.

\section{Parenthetical Constituents in Dimmesdale’s Narrative Sentences}

SE MCL [ ${ }_{P P}^{A}\left({ }_{p}^{\text {Notwithstanding }} \underset{G P}{M}\left(\begin{array}{l}H \\ p n\end{array}\right.\right.$ his $)\left\langle\begin{array}{l}M \\ A j\end{array}\right.$ high ${ }_{A j}^{M}$ native ${ }_{N}^{H}$ gifts ${ }_{c j}$ and $\underset{A j}{M}$ scholar-like ${ }_{N}^{H}$ attainments $\left.\rangle\right),{ }_{N P}^{S}$ (there ) ${ }_{V P}^{P}$ (was) ${ }_{N P}^{S}\left({ }_{d}^{M} \underset{\text { an }}{H}{ }_{\text {air }}^{H} \underset{P P}{\left({ }_{p}\right.}\right.$ about ${ }_{d}^{M}$ this

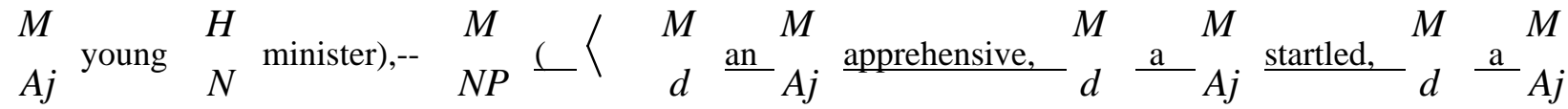

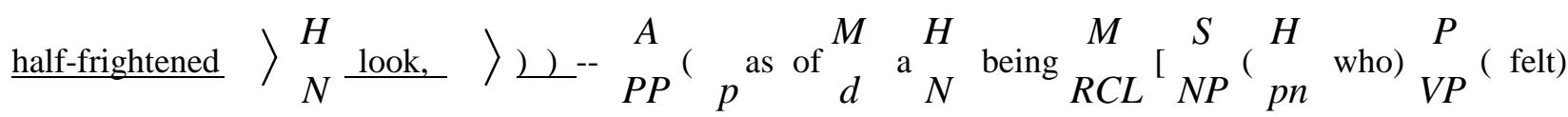

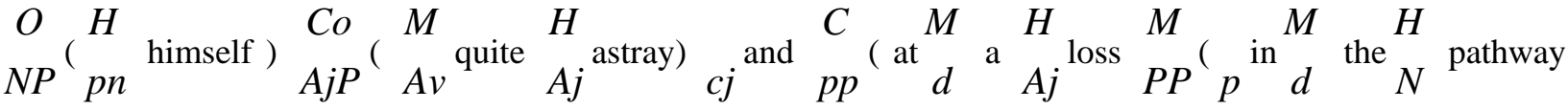
${ }_{P P}^{M}{ }_{p}$ of ${ }_{A j}^{M}$ human ${ }_{N}^{H}$ existence) $\left.\left.)\right) ~\right\rangle,{ }_{c j}$ and $\underset{R C L}{M}{ }_{V P}^{P}$ (could $\underset{A v P}{A} \underset{A v}{H}$ only) be) ${ }_{P P}^{A}{ }_{p}^{\text {at }}$ $\underset{N}{H}$ ease ${ }_{P P}^{M}\left({ }_{p}\right.$ in ${ }_{A j}^{M}$ some ${ }_{N}^{H}$ seclusion $\underset{P P}{M}\left({ }_{p}\right.$ of ${ }_{G P}^{M} \underset{p n}{H}$ his $) \underset{p n}{H}$ own $\left.\left.\left.\left.\left.)\right)\right)\right] ~\right\rangle\right)$. ] Ch.3 Se.41

(1) Hawthorne's use of the parenthetical structure here is significant since it gives the reader the writer's opinion about Dimmesdale. It is a description about the look of the minister. The parenthetical constituent appears in a form of noun phrase in apposition. Instead of saying... there was an air about this young minister..., Hawthorne adds a noun phrase and says... there was an air about this young minister, an apprehensive, a startled, a half-frightened look,... to give the reader the source of this air. From where does it come? It comes from Dimmesdale's look which is "apprehensive", "startled", and "half-frightened" (Hawthorne, 1992, p. 69). The head of the noun phrase look is pre-modified with sex modifiers three of which are determiners while the rest are adjectives that assign features to Dimmesdale's look and make them part of his identity.

(2) At the same time, Hawthorne's (1992) aim of employing this parenthetical structure is to give the reader 
a hint about Hester's "fellow-sinner and fellow-sufferer" (p. 69). The minister's "half-frightened look" indicates that he has done something seriously wrong. Later on, during the course of the novel, he turns out to be Hester's guilty partner. So, he is condemned by everything he does: by every gesture he makes, by every step he takes, and by every word he utters. Notably, the writer's use of the stylistic feature of the parenthetical structure guides the readers towards better understanding of Dimmesdale's character and hence better interpretation of the whole meaning of The Scarlet Letter. This asserts the idea that analyzing the form, the grammatical structures of sentences, leads to deepening the readers' awareness of the content, i.e., it leads to better understanding of texts by providing deep levels of meanings.

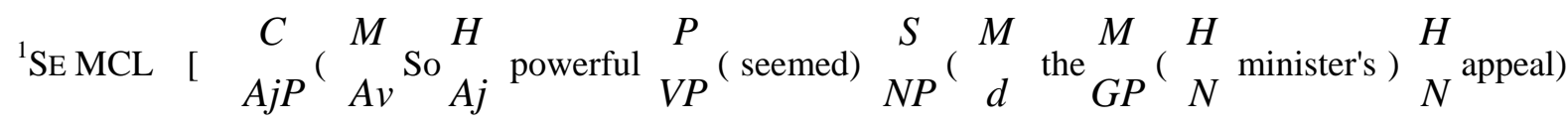

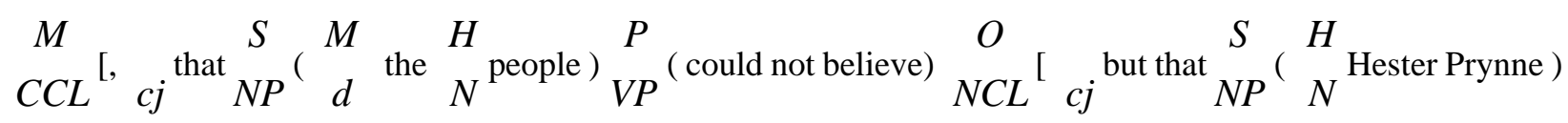

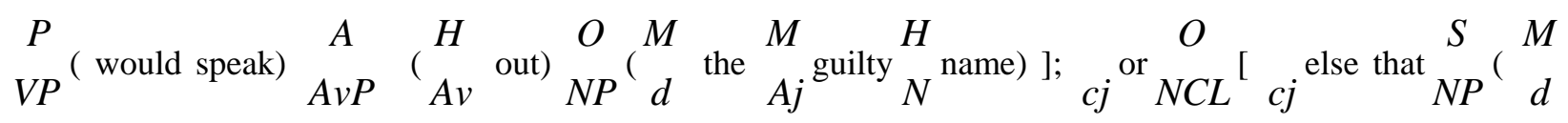

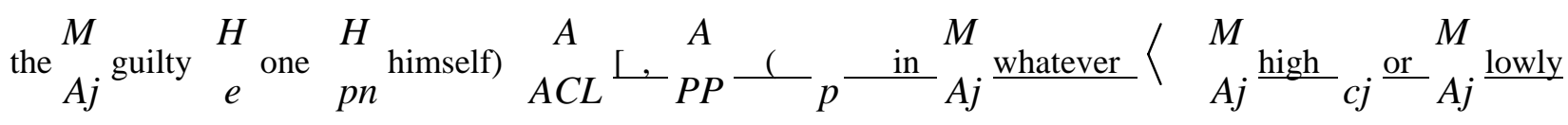

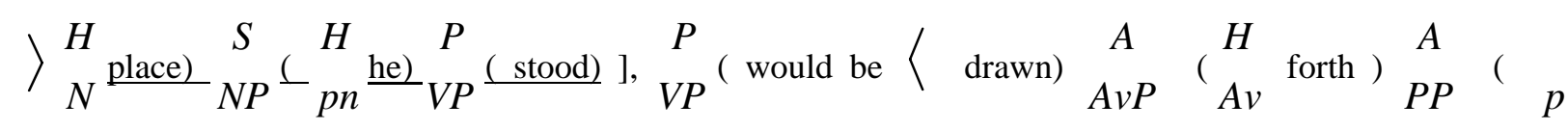
$\underset{b y}{M}$ an $\left\langle{ }_{A j}^{M} \text { inward }{ }_{C j} \text { and }{ }_{A j}^{M} \text { inevitable }\right\rangle_{N}^{H}$ necessity), $\underset{c j}{\text { and }} \underset{V P}{P}$ ( compelled) $\underset{N C L i}{O}{ }_{V P}^{P}$ (to ascend) $\underset{N P}{O}\left({ }_{d}^{M}\right.$ the ${ }_{N}^{H}$ scaffold ) ] $\left.\left.\rangle\right\rangle\right)$. ] Ch.3 Se.48.

(1) Hawthorne's use of the parenthetical structure in a form of an adverb clause that indicates the all possible status (high or lowly) of Hester's guilty partner's position reflects his concern with confirming the minister's appeal, which resulted from his convincing speech, on the part of the audience. So whatever his status is, the guilty partner, affected by the minister's powerful speech, will stand beside Hester on the scaffold. It must be noted that Hawthorne emphasizes the minister's appeal by his fronting of the complement in the main syntactic structure. Not only does Hawthorne emphasize this appeal by fronting the complement so powerful, but also he makes further reinforcement by the employment of another stylistic feature, that is the use of parenthetical constituent. So, it is as if, his use of parenthetical structure echoes his use of fronting of the

\footnotetext{
${ }^{1}$ This sentence represents Hawthorne's comment on Dimmesdale's pleading to Hester to reveal the identity of her secret lover, when he is asked, as being her spiritual guide, to urge his parishioner, Hester Prynne, to give the name of her daughter's father.
} 
complement in its aim. In other words, the writer's aim of fronting the complement is the same as his aim of using the parenthetical structure that is confirming the minister's appeal which comes from his speech that urge Hester to name her guilty partner.

(2) Hawthorne's choice of the pattern of the parenthetical constituent is significant. The significance of the parenthetical constituent comes from its syntactic structure. It is a finite adverb clause. This structure allows Hawthorne to front the prepositional phrase adverb, and thus he brings it into focus emphasizing the two possible status of the position of Hester's guilty partner: high or lowly.

So thanks to the minister's appeal, Hester's guilty partner will disregard his place in society, and hence stand on the pedestal of shame beside Hester Prynne. One should say that the communicative stylistic effect will be different if Hawthorne uses a non-finite clause as: standing in high or lowly place. First, it will be analyzed, according to the system used in the book of Leech et al. (1982), as a non-restrictive relative clause and in this case it will be part of the syntactic structure of its preceding noun phrase structure, i.e., it will be a modifier of the head guilty one. Second, this structure, the non-finite clause which starts with the predicator, will not allow Hawthorne to front the prepositional adverbial phrase and hence it will not allow him to bring it (the prepositional adverbial phrase) into focus emphasizing what he wants to emphasize. Therefore, it (the non-finite clause) will create a different communicative effect than what the writer wants to communicate. So, apparently, a different internal syntactic structure of the parenthetical constituent which results from the writer's choice of another kind of clause loses the sentence its effective meaning, because it (the non-finite clause) will create another effect that results from its different internal syntactic structure. One can conclude that Hawthorne's use of parenthetical constituent as a stylistic feature that serves his aim of creating a certain communicative effect as well as his choice of the pattern of his employed parenthetical constituent is successful since they create his designated effect on the reader, an effect which can not be achieved by the writer's use of another stylistic feature or another syntactic structure.

${ }^{2}$ SE MCL $\quad\left[\quad A \underset{A v P}{\left({ }_{A v}^{H}\right.}\right.$ Yet) ${ }_{N P}^{S}\left(\begin{array}{l}H \\ N\end{array}\right.$ Mr. Dimmesdale ) ${ }_{V P}^{P}$ (would $\underset{A v P}{A}\left(\begin{array}{l}H \\ A v\end{array}\right.$ perhaps ) have seen )

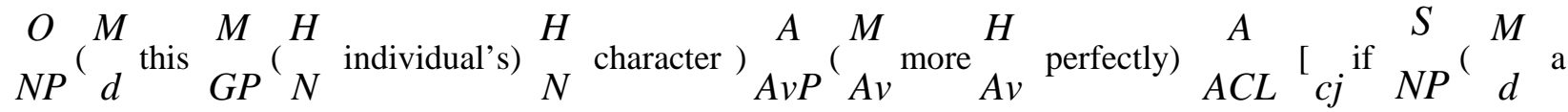

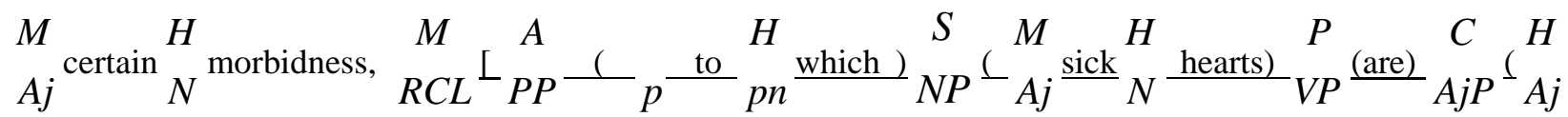

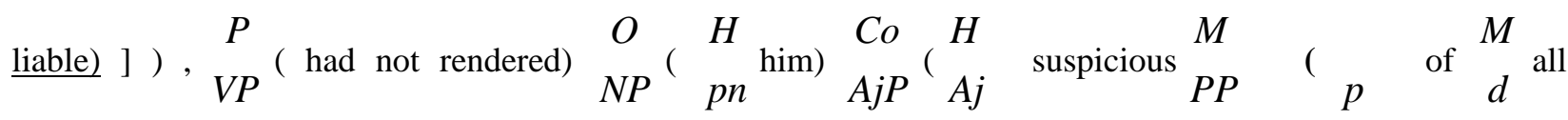
$H$ $N$ mankind) ). ] Ch.10 Se.13.

\footnotetext{
${ }^{2}$ In this sentence, individual's character refers to Roger Chillingworth’s character.
} 
(1) Hawthorne's use of the parenthetical structure to which sick hearts are liable is significant since it assigns a feature to the head morbidness and makes it part of its identity. At the same time, the parenthetical structure appears in a form of a subordinate non-restrictive relative clause which employed by Hawthorne to make the reader accepts the piece of the information that Dimmesdale's sick heart is responsible for his morbidness as a fact that needs no argument. Dimmesdale's morbidness which results from his sick heart makes him suspicious of all people, therefore; he is unable to understand the evil character of Chillingworth.

The sickness of Dimmesdale's heart results from his violation of God's law by the commission of the sin of adultery. Apparently, this sin causes him a deep sense of estrangement which makes him, in life, unable to recognize his enemy from his friend as well as isolates him from "a truly intimate relationship with his flock" (Mathews, 1957, pp. 288-289). Later on, Hawthorne (1992) emphasized the sickness of Dimmesdale’s heart that spread to include all "his heart's entire substance” (p. 145). This sickness is responsible for his being unable to realize the fact that Chillingworth is his worst enemy. He hates everything related to the old man, as Hawthorne (1992) commented:

His gestures, his gait, his grizzled beard, his slightest and most indifferent acts, the very fashion of his garments, were odious in the clergyman's sight; a token, implicitly to be relied on, of a deeper antipathy in the breast of the latter than he was willing to acknowledge to himself. (p. 145)

Although he is conscious that there is an evil influence upon him caused by Chillingworth, he is unable to give an interpretation for that feeling. Being unable to assign a reason for such hatred, Dimmesdale attributes all his hatred and antipathy of the old man to the sickness which is in heart. Hawthorne (1992) said: "For, as it was impossible to assign a reason for such distrust and abhorrence, so Mr. Dimmesdale, conscious that the poison of one morbid spot was infecting his heart's entire substance, attributed all his presentiments to no other cause” (p. 145). The previous sentence is parsed as follows:

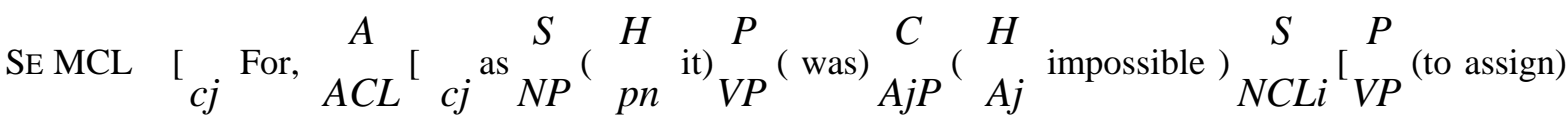

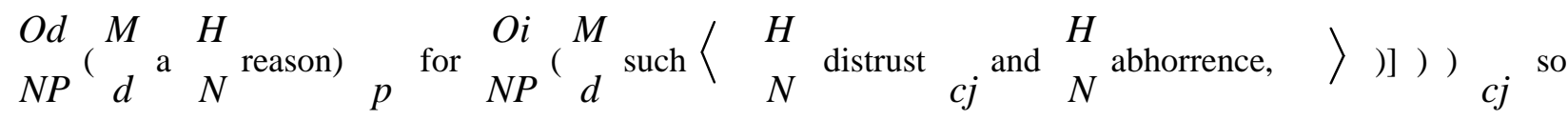

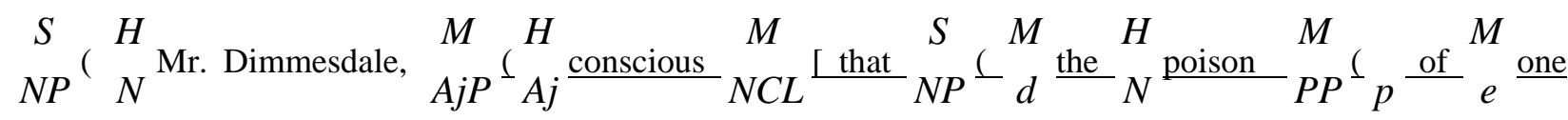

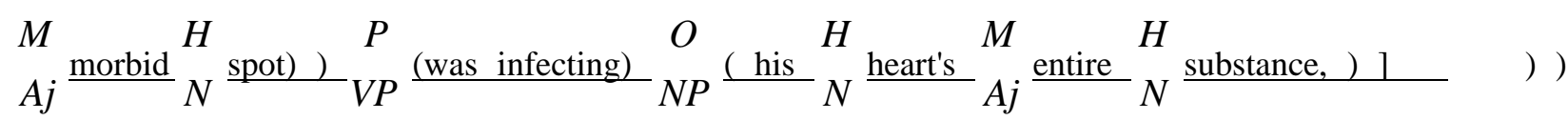

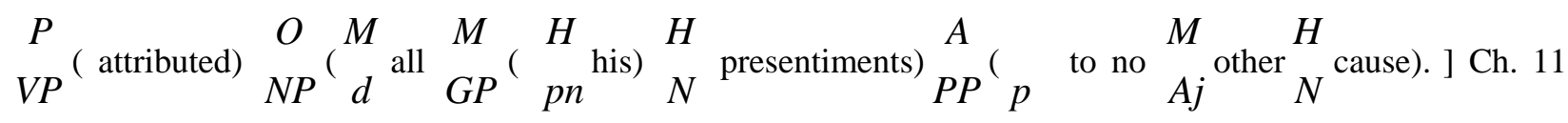
Se. 22. 
Hawthorne's use of the adjective phrase that modifies the head Mr. Dimmesdale makes the reader accepts the idea that Dimmesdale is conscious of the sickness of his heart which spread as a poison from one spot to another until it includes all the internal substance of his heart.

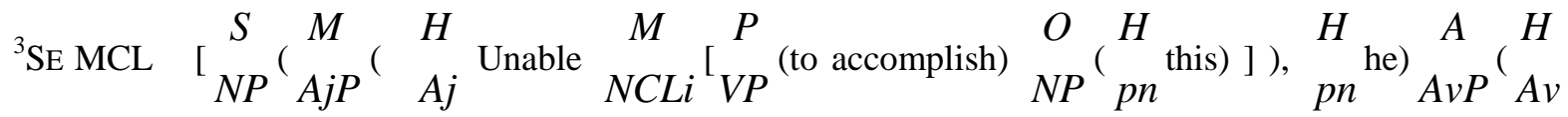
nevertheless, ) ${ }_{P P}^{A}\left({ }_{p}\right.$ as ${ }_{d}^{M}$ a ${ }_{N}^{H}$ matter ${ }_{P P}^{M}{ }_{p}$ of $\begin{array}{l}H \\ N\end{array}$ principle, ) ) ${ }_{V P}^{P}$ (continued) $\underset{N P}{O}{ }_{G P}^{M}\left(\begin{array}{l}{ }_{p n}^{H} \\ \text { his })\end{array}{ }_{N}^{H}\right.$ habits ${ }_{P P}^{M}\left({ }_{p}\right.$ of ${ }_{A j}^{M}$ social ${ }_{N}^{H}$ familiarity $\left.)\right){ }_{P P}^{A}{ }_{p}$ with ${ }_{d}^{M}$ the ${ }_{A j}^{M}$ old ${ }_{N}^{H}$ man),

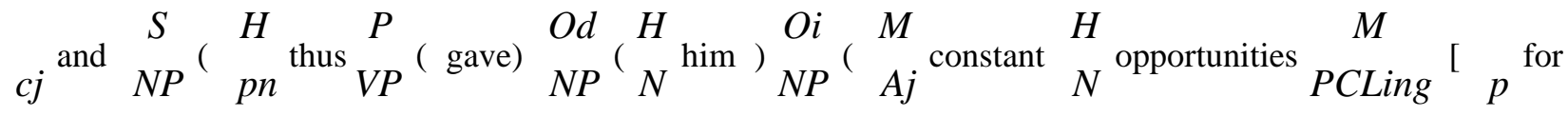

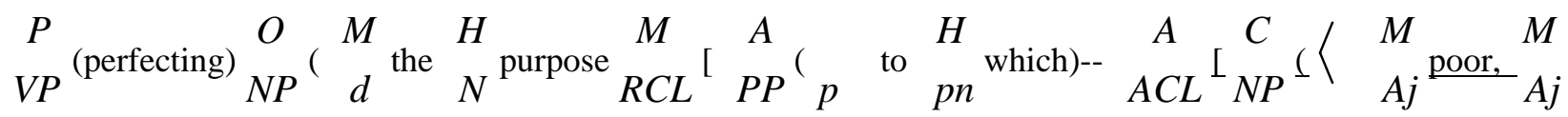

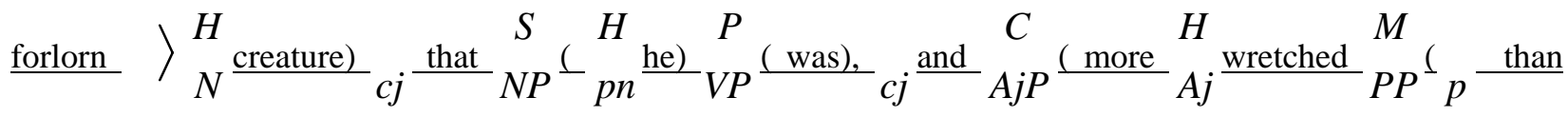

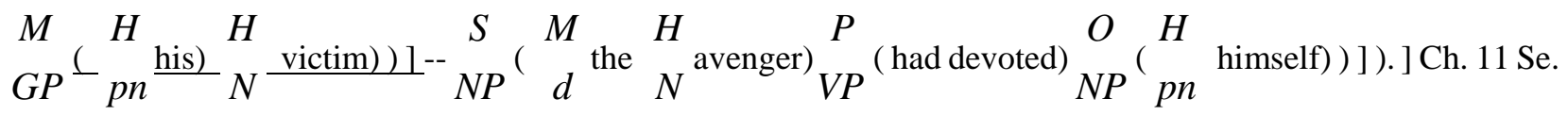
24.

(1) The use of the parenthetical structure in this sentence is successfully employed by Hawthorne to give the reader the piece of the information that Dimmesdale is a wretched person. It must be noted here, that the syntactic structure of the main pattern is related to Dimmesdale. In other words, the main subject of the sentence is Dimmesdale, hence the main meaning is related to Dimmesdale. Apparently, the writer's parenthetical structure is related to Roger Chilling. Hawthorne's emphasizes the idea that Chillingworth is a poor and a forlorn person by fronting the complement inside the structure of the adverb clause. What must be noted here is Hawthorne use of the adjective phrase more wretched than his victim. It presupposes the misery of Dimmesdale. Although, it does not state, directly, that Dimmesdale is a wretched person, the reader can detect this implied information depending on the syntactic structure of the sentence as well as its meaning. At the same time, the writer's use of a parenthetical structure that is related, primarily, in meaning to Chillingworth and presupposes a fact about Dimmesdale, in a syntactic pattern of a sentence which is mainly related to Dimmesdale reflects the relationship between Dimmesdale and Chillingworth. It is a connected relationship in which the physician

\footnotetext{
${ }^{3}$ He refers to Dimmesdale while the old man is Chillingworth.
} 
becomes "the shadow of Dimmesdale" (Fiedler, 1982, p. 437). This shadow is a source of eternal woe and misery. Hawthorne's also conveys the meaning that Roger Chillingworth is more wretched that Dimmesdale, because he always seeks revenge, and by doing that he turns into a devil or a vampire who sucks the poor minister's soul by unlawful operation that lead to his damnation. Chillingworth is not aware that by his act of torturing the minister's soul, he himself falls into damnation.

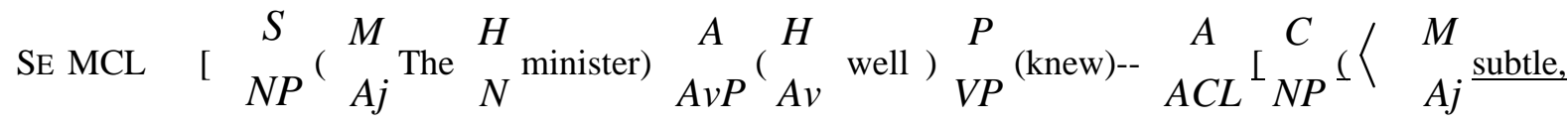

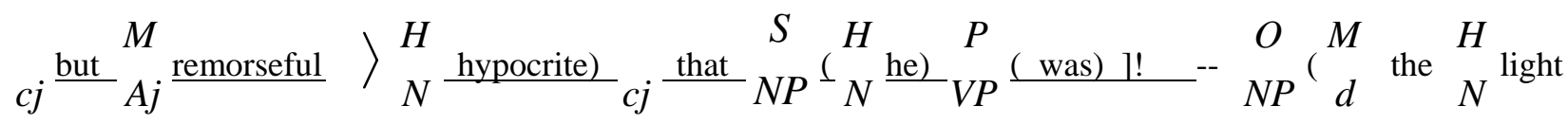

$$
\begin{aligned}
& \underset{R C L}{M}{ }_{P P}^{A} \quad\left(\quad p \quad \text { in }{ }_{p n}^{H} \text { which) }{ }_{N P}^{S}\left(\begin{array}{l}
M \\
G P
\end{array}\left(\begin{array}{l}
H \\
p n
\end{array} \text { his }\right){ }_{A j}^{M} \text { vague }{ }_{N}^{H} \text { confession }\right) \underset{V P}{P}\right. \text { (would be }
\end{aligned}
$$

viewed) ] ). ] Ch. 11 Se. 62.

(1) Hawthorne's use of the parenthetical structure subtle, but remorseful hypocrite that he was reflects the hypocrisy of the minister. Even the internal pattern of the adverb clause that represents the parenthetical structure reflects and emphasizes that hypocrisy. The noun phrase that functions as a complement in the structure of the adverb clause is fronted. Hawthorne fronts it to bring it into focus and thus he emphasizes the subtlety and, more importantly, the remorse that are connected with Dimmesdale's hypocrisy.

(2) Hawthorne constructs the parenthetical structure in a form of a subordinate adverb clause to make the reader accepts the idea that the minister is a subtle as well as a remorseful hypocrite without any doubt. As a result, one can say that the internal grammatical structure is responsible for communicating the effect which the writer wants to convey to the reader. The parenthetical structure reflects and, more importantly, asserts the hypocrite character of the minister, and hence, it sheds light on the theme of hypocrisy. Dimmesdale himself is aware that he is going to be a hypocrite. In his appeal, very near the beginning of the novel, to Hester Prynne to speak out the name of her guilty partner, Dimmesdale does not really want her to reveal his identity. Hawthorne (1992) said, on Dimmesdale's tongue:

If thou feelest it to be for thy soul's peace, and that thy earthly punishment will thereby be made more effectual to salvation, I charge thee to speak out the name of thy fellow-sinner and fellow-sufferer! Be not silent from any mistaken pity and tenderness for him; for, believe me, Hester, though he were to step down from a high place, and stand there beside thee, on thy pedestal of shame, yet better were it so, than to hide a guilty heart through life. What can thy silence do for him, except it tempt him—yea, compel him, as it were—-to add hypocrisy to sin? (pp. 69-70)

Even though the minister is pleading to Hester to give the name of her fellow sinner, he does not really want her to reveal her fellow sinner's identity. He himself gives the consequences of his silence and therefore reveals his hypocrisy. He knows what will happen to him if he endures his sin in private, but he is, at this point in the novel, too weak and cowardly to admit his sin. Consequently, during the course of the novel, Dimmesdale gives reasons for his silence with some reference to his need to be a good preacher, as Johnson (1981) said: “[Dimmesdale] rationalizes his every failure, with some reference to his need to be an effective minister” (p. 63). 
Even, at the end of the novel, on election day, he does reveal the secret of his sin, but, apparently, he does so at his dying moment not because he is a strong man, but to absolve his soul. Were he a strong man, he would, like Hester, have come forward with his secret, instead of allowing it to slowly destroy him.

Dimmesdale's anguish and suffering give him a new power of convincing the people around him, consequently this new gift makes his appeals and sermons to people emotionally powerful. His colleagues, the other priests, are excellent scholars, but they lack "the tongue of flame", the power of effective speech, "of addressing the whole human brotherhood in the heart's native language” (Hawthorne, 1992, p. 147). By a curious ambiguity, Dimmesdale's torture and suffering make him a better priest than he was in the past. People now gather to listen to him. They believe that he is a saint, “a miracle of holiness” (Hawthorne, 1992, p. 147). To them, he is "the ambassador of God, bringing his messages of wisdom, and rebuke, and love” (Lall, 1970, p. 47). As a result, they never believe that he is a sinner even if Dimmesdale himself tell them that he is the worst sinner of them all. On the contrary, they worship, love, and respect him more.

I, whom you behold in these black garments of the priesthood,- - I, who ascend the sacred desk, and turn my pale face heavenward, taking upon myself to hold communion, in your behalf, with the Most High Omniscience,-I, in whose daily life you discern the sanctity of Enoch-I, whose footsteps, as you suppose, leave a gleam along my earthly track, whereby the pilgrims that shall come after me may be guided to the regions of the blest,- $-\mathrm{I}$, who have laid the hand of baptism upon your children,- - I, who have breathed the parting prayer over your dying friends, to whom the Amen sounded faintly from a world which they had quitted,-I, your pastor, whom you so reverence and trust, am utterly a pollution and a lie! (Hawthorne, 1992, p. 148)

These partial confessions just make him, in his self-eye, more of a hypocrite. He knows how the parishioners will interpret these confessions; he is not blind to their looks of adoration and respect. Hawthorne (1992) said:

More than once-nay, more than a hundred times... He had told his hearers that he was altogether vile, a viler companion of the vilest, the worst of sinners, an abomination, a thing of unimaginable iniquity; and that the only wonder was, that they did not see his wretched body shrivelled up before their eyes, by the burning warth of the Almighty!... They heard it all, and did but reverence him the more... He had striven to put a cheat upon himself by making the avowal of a guilty conscience, but had gained only one other sin, and a self-acknowledged shame, without the momentary relief of being self-deceived. He had spoken the very truth, and transformed it into the veriest falsehood. And yet, by the constitution of his nature, he loved the truth, and loathed the lie, as few men ever did. Therefore, above all things else, he loathed his miserable self! (p. 149)

Obviously, Dimmesdale's congregation generally interprets his sermons and confessions allegorically rather than as expressions of any personal guilt, because they depend in their interpretation on the priest's background and his penchant for rhetorical speech. This attitude of the congregation drives Dimmesdale to further internalize his guilt and also self-punishment and leads to more deterioration in his physical and spiritual conditions.

To conclude, one can say that Dimmesdale is unable to confess his guilt. This gives him no inward peace and leads to his suffering and torture which in turn open up his mind and allow him to empathize with others. Consequently, his flock always loves and adores him. They are emotionally connected with him to the degree that, they become not only deaf in front of his confession, but also blind to his miserable, wretched state. Instead of realizing Dimmesdale's reality of being a sinner, they, very far away from the reality, regard him “the godly youth!”, “the saint on earth!” (Hawthorne, 1992, p. 149). This sharpens Dimmesdale's suffering of being, in his self-eye, a subtle hypocrite. What must be said is that Hawthorne is able to convey all these 
meanings with his stylistic use of parenthetical structure. As if he summarizes all the suffering of Dimmesdale and conveys it by the use the adverb clause: subtle, but remorseful hypocrite that he was. The subtlety of Dimmesdale results from his creation, even if it is not his intention, of the thwarted interpretation of his congregation who interprets his confessions allegorically rather than as real expressions of sin. The remorse results from his sin and its consequences of being a hypocrite. To sum up, one can say that Hawthorne's employment of the parenthetical structure is successful, not only, in conveying the writer's designated effect on the reader, but, more importantly, in providing the reader with deep understanding of Dimmesdale's character as well.

SE MCL [ ${ }_{P P}^{A}\left({ }_{p}\right.$ On ${ }_{e}^{H}$ one ${ }_{P P}^{M}{ }_{p}{ }_{\text {of }}^{M} d$ those ${ }_{A j}^{M}{ }_{N}^{\text {ugly }}{ }_{N}^{H}$ nights, ${ }_{R C L}^{M}{ }_{N P}^{O}{ }_{p n}^{H}{ }_{-}^{\text {which })}\langle$

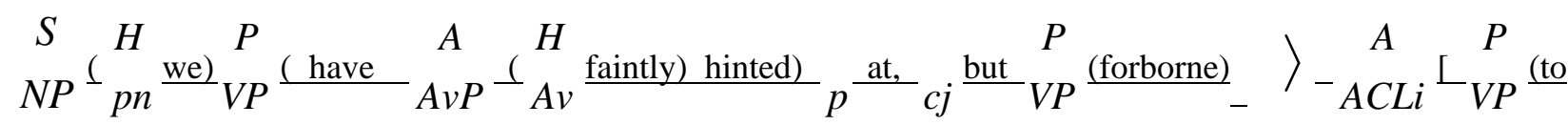

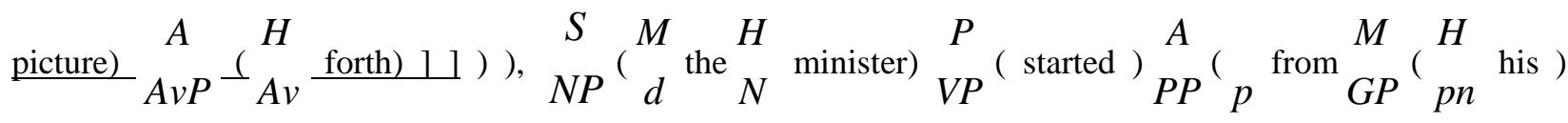
$H$
$N$ chair). ] Ch.11 Se.86.

(1) The parenthetical structure is a non-restrictive relative clause that functions as a postmodifier of the head nights with the aim of assigning features to this noun and making them part of its identity. Hawthorne assigns the feature of ugliness to the head nights by his use of the adjective ugly as a premodifier, but to achieve his aim of exaggerating the sense of ugliness of Dimmesdale's nights, he adds a post modifying structure of the head nights. The relative clause is a subordinate clause that allows its piece of information to be treated as a fact that requires no question on the part of the reader. Hence, the reader accepts that Hawthorne only faintly hinted at these ugly nights but forborne to picture forth. By accepting that, the reader realizes the great degree of ugliness of Dimmesdle's nights. Dimmesdle is not able to confess his sin. So he is oppressed with the weight of the sexual sin which he covertly committed with Hester. Deep in his heart he feels that he sinned against God, and society, and this feeling burns his conscience, leads him to constant torment and gives him no inward peace. Commenting on Dimmesdale’s state, Loring (1961) said:

[The minister] was halting, and wavering, and becoming more and more perplexed and worn down with woe, because he had violated the dignity of his position and had broken a law which his education had made more prominent than any other law in his soul. (p. 155)

Dimmesdale is weakening more each day because of the guilt that he has inside of his heart. Being unable to confess his guilt, Dimmesdale subjects himself to various kinds of penance, including vigils, fasts, and flagellations. The writer describes the minister's nights as ugly nights because they are full of different kinds of torture. In an attempt to compensate for his sin, Dimmesdale locks himself in his room. This self-debasement 
extends to the degree of scourging himself until he sees his blood. In doing that, he laughs bitterly in self-mockery. He also, as a sort of tormenting himself, fasts rigorously until his knees become so weak that they tremble beneath him. In addition, he keeps lengthy, nightly vigils during which he has various visions and hallucinations. So, apparently, Dimmesdale's punishment comes purely from inside. His crime, adultery, is responsible for his fall. As Waggoner (1955) observed: “[Dimmesdale] descends from his original position as the saintly guide and inspiration of the godly to the position he occupies during the greater part of the novel as very nearly the worst of the sinners” (p. 143).

(2) Hawthorne's employment of the parenthetical structure is essential in creating the complexity of the structure of the sentence. If it is omitted, the complex sentence will be a simple one. It is also responsible for making the complex structure a periodic structure because it appears at the beginning of the sentence, i.e., it is an anticipatory constituent which is non-final. At the same time, the parenthetical structure creates a sense of suspense on the part of the reader because it goes against the memory principle so the reader has to keep it in his memory until the end of the sentence to be able to decode its message. This syntactic burden on the reader's memory creates dramatic effect. The reader is eager to know what happens in one of these ugly nights, which the writer has "faintly hinted at but forborne to picture forth" (Hawthorne, 1992, p. 151). So, Hawthorne's sentence is a periodic sentence that has a dramatic quality. It combines as Leech and Short (1981) observed: "The principle of climax with the principle of subordination, and so [progresses] from a build-up of tension to a final climatic point of resolution” (p. 226). So, for the previous reason, one agrees with the idea that assumes that periodic structure has been regarded as "an influential model in the history of prose writing" (Leech \& Short, 1981, p. 226). Hawthorne's employment of the parenthetical structure, which is a subordinate clause in the first element of the structure, i.e., the adverb, is responsible for making vertical complexity in left-branching and this "seems to make for more complexity than embedding at the end ('right-branching')" (Leech et al., 1982, p. 137).

SE MCL [ ${ }_{c j}$ And ${ }_{A v P}^{A}\left(\begin{array}{l}H \\ A v\end{array}\right.$ thus), ${ }_{A C L i n g}^{A}{ }_{A v P}^{A}{ }_{A v}^{H} \stackrel{\text { while })}{P} V P^{\text {(standing })}{ }_{P P}^{A}{ }^{(}{ }^{\text {on }}$

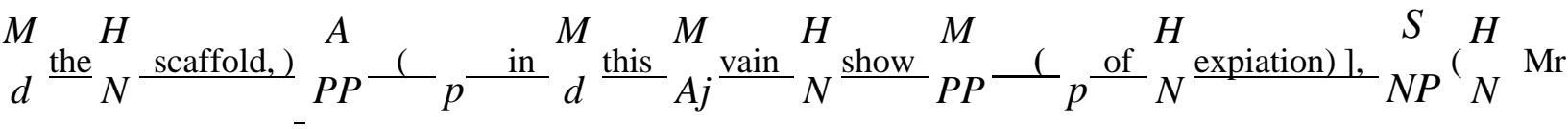
Dimmesdale) ${ }_{V P}^{P}$ ( was overcome) ${ }_{P P}^{A}$ ( ${ }_{p}$ with ${ }_{d{ }^{\mathrm{a}}{ }_{A j}{ }^{\text {great }}{ }_{N}^{H}}^{M}$ horror ${ }_{P P}^{M} \quad\left({ }_{p}\right.$ of ${ }_{N}^{H}$ mind) $)$,

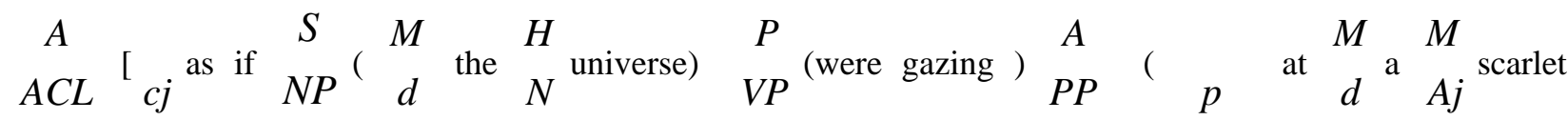

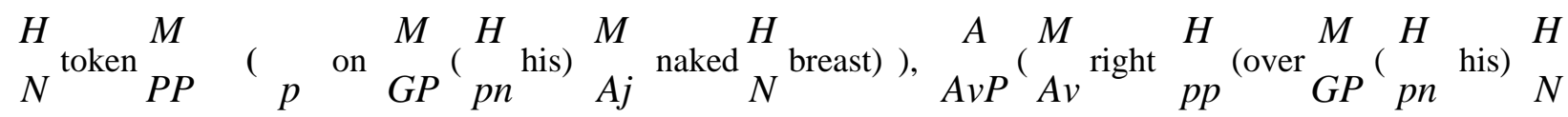
heart) ) ]. ] Ch.12 Se.19. 
(1) Hawthorne's use of the parenthetical structure is very significant since it functions as an adverb clause that gives a circumstantial background to the meaning of the sentence. The writer makes the piece of the information that Dimmesdale was standing on the scaffold, during night time, in vain public show of expiation a presupposed, accepted fact on the part of the reader by putting it in a subordinate clause.

(2) The use of the parenthetical structure creates a sense of suspense, because the reader has to keep it in his mind until decoding its message by reading the rest of the sentence. Therefore, Hawthorne's use of the parenthetical structure is successfully employed to create a dramatic effect on the reader. The reader is eager to know what Mr. Dimmesdale will do after his standing on the platform of the pillory during night time, ironically in front of no one except the elements of nature. Dimmesdale, who has been in a very terrible psychological state that resulted from his way of using different methods to torture himself and his lengthy vigil that makes his mind unstable to a degree of having hallucinations of different visions, is horrified because he believes that the whole universe is gazing at The Scarlet Letter on his breast.

(3) Hawthorne's choice of the modifier vain inside the syntactic structure of the parenthetical structure is significant. It reflects the useless attempt of Dimmesdale's action of standing on the scaffold on a gloomy, cold night. As Hawthorne (1992) said: "[Dimmesdale] had been driven hither by the impulse of that Remorse which dogged him everywhere” (p. 153). Apparently, under the pricks of his conscious, Dimmesdale mounts the scaffold to confess his sin but ironically, he only shows himself to the elements of nature.

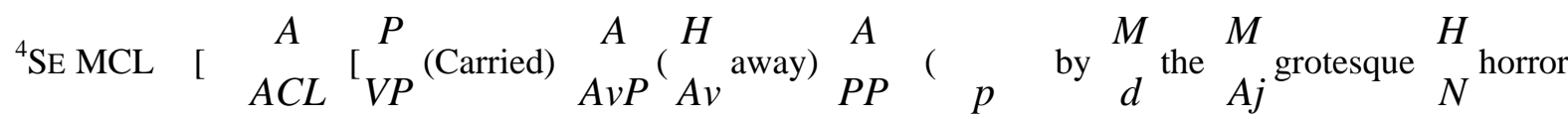

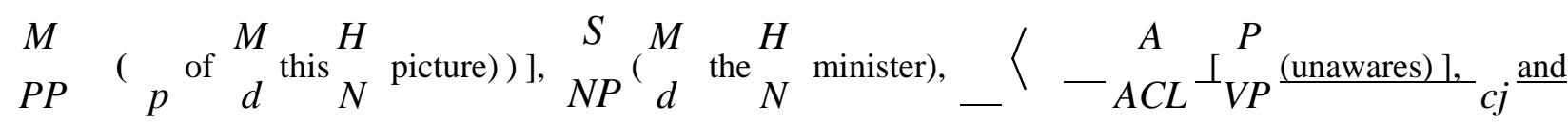

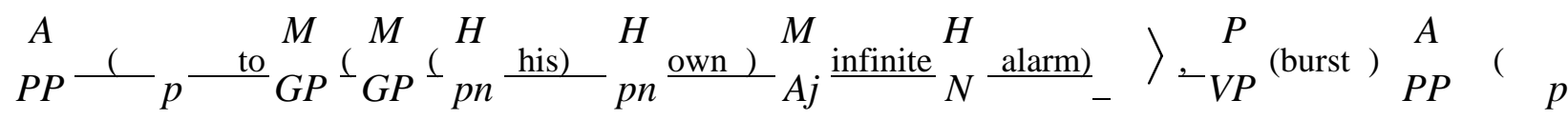

$$
\begin{aligned}
& \text { into }_{d}^{M}{ }_{\text {a }}^{M}{ }_{A j}^{\text {great }}{ }_{N}^{H} \text { peal }{ }_{P P}^{M} \quad\left({ }_{p} \text { of }{ }_{N}^{H} \text { laughter) }\right) \text {. ] Ch.12. Se. } 69 .
\end{aligned}
$$

Hawthorne's use of the parenthetical structure reflects the minister's terrible mind as well as his distressed state while he is standing on the scaffold in useless attempt to confess his sin. It consists of two adverbs. The first adverb is an adverb clause which consists of only one phrase that is the verb phrase unawares. Hawthorne's choice of using the adverb phrase is significant, because it reflects his aim of concentrating on Dimmesdale's mental state. Hawthorne favors using a structure of subordinate clause, because it allows him to convince the reader with the piece of the information of the minister's unawareness. Dimmesdale is unaware when he bursts into laughter. While the second adverb is a prepositional adverbial phrase that gives a circumstantial background to the main

\footnotetext{
${ }^{4}$ This sentence appears in the context of the second scaffold scene when Dimmesdale has a great horror of being discovered because of his outcry.
} 
action that is bursting into laughter. Hawthorne (1992) successfully employed his use of parenthetical structure in reflecting the involuntary action of Dimmesdale, which results from his deep agony of being unable to confess his sin, while standing on the scaffold in "vain show of expiation" (p. 153). After failing to respond to Bellingham, Mistress Hibbines, or Wilson, Dimmesdale "reacts involuntarily this time to burst into a pearl of insane laughter" (Gerber, 1944, p. 41). Dimmesdale's reluctance leads to his inability to choose or decide, and this in turn leads to his distressed state which, if continues, will lead to insanity represented by his involuntary actions.

\section{Discussion}

The stylistic feature of the use of parenthetical structure is successfully employed by Hawthorne in Dimmesdale's narrative sentences. By using the parenthetical constituents, Hawthorne conveys to the readers the deep agony of the minister, that results from his sin, and the effects of his sin on his life, that, in the author's opinion, more importantly, lead to his hypocrisy. This is the general thread of meaning for which the writer uses the stylistic feature of parenthetical constituent, because, from the sentences examined, one finds that Hawthorne's use of the parenthetical structure in each narrative sentence does not vary notably, from one sentence to another in its meaning that generally reflects the suffering and the hypocrisy of Dimmesdale. The interpretations of the parenthetical structure revolve around the writer's intention of doing the following: reflecting Dimmesdale's suffering, indicating the sickness of his heart, conveying his wretched nature, communicating his remorse, showing his vain attitude of expiation, numerating his methods of torturing himself, and, more importantly, unmasking his hypocrisy. While, what varies notably from one sentence to another in Dimmesdale's narrative sentences is the internal grammatical structure of the parenthetical constituents employed by Hawthorne. He uses NP phrase in apposition, prepositional adverb phrase, adjective phrase, finite and non-finite adverb clause, and non-restrictive relative clause. Even the internal syntactic structures of the same functional structure vary from one sentence to another according to the effect which the writer wants to create on the reader, for example, the internal grammatical structure of the adverb clause, which is used as parenthetical constituent in one sentence, differs from that used in another sentence also as an adverb clause, i.e., the patterns of the same grammatical structures are different. They differ from one sentence to another to achieve the writer designated effect on the reader, an effect which cannot be achieved, as illustrated in the stylistic analysis, by the use of another stylistic feature or another internal grammatical structure. Consequently, any change in the internal grammatical structure of the parenthetical constituent used in any sentence of Dimmesdale's sentences loses the sentence, its meaning, as well as the designated effect that the writer wants to create to his readers. Hence, the forms of the parenthetical constituents which Hawthorne uses in Dimmesdale's narrative sentences reinforce the meanings that the writer wants to convey to his readers about Dimmesdale's character.

\section{Conclusions}

Hawthorne uses a complex style in reflecting Dimmesdale's character with all its dimension of hesitation, hypocrisy, suffering, agony, and torture. In this complex style, complexity of structure tends to occur at the end of the syntactic structure of the narrative sentences. Sentences that are devoted to the revelation of Dimmesdale's character have various stylistic features which are extracted from the syntactic analysis. These stylistic features are as follow: embedding (the process itself), retaining the most complex structure to the end of the sentence, 
fronting (subject, object, or complement), delaying (any structure), post modification of the head of the s., o., or c. (any structure) and use of parenthetical constituent.

The aforementioned stylistic features represent group one which Hawthorne uses with high proportions in comparison with the stylistic features of group two which he does not use so much: periodic sentences, distancing structurally related items, split constituent, subject-verb inversion, extraposition (of clausal subject), use of NP phrase in apposition, and postponement of post modifier.

Also, from the study, one can conclude that the stylistic feature of the use of parenthetical structure is successfully employed by Hawthorne in the narrative sentences that are devoted to the reflection of the minister's aspects of character. This stylistic feature is used by Hawthorne to convey to the readers the deep agony of the minister, which results from his sin of adultery, and the effects of his sin on his life. This sin leads to his hypocrisy. This is the general thread of the meaning for which Hawthorne employs the stylistic feature of parenthetical constituent, because, from the sentences examined, one can say that Hawthorne's use of the parenthetical structure in each narrative sentence does not vary notably, from one sentence to another in its meaning. The meaning of each sentence generally reflects the agony and the hypocrisy of Dimmesdale. Hawthorne uses the parenthetical structure to reflect the suffering, the sickness, the misery, the remorse, the vain attitude of expiation, and, more importantly, the hypocrisy of Dimmesdale. So, one can say that the meanings which the parenthetical structures reflect do not vary notably from one sentence to another. What varies notably from one sentence to another in Dimmesdale's narrative sentences is the internal grammatical structure of the parenthetical constituents employed by Hawthorne. The writer uses NP phrase in apposition, prepositional adverb phrase, adjective phrase, finite and non-finite adverb clause, and non-restrictive relative clause. Even the internal syntactic structures of the same functional structure vary from one sentence to another according to the effect which Hawthorne wants to create on the reader, for example, the internal grammatical structure (the pattern) of the adverb clause, which is used as parenthetical constituent in one sentence, differs from that used in another sentence also as an adverb clause. They differ from one narrative sentence to another to achieve the writer designated effect on the reader, an effect which cannot be achieved by the use of another stylistic feature or the use of another internal grammatical structure. Therefore, any change in the internal syntactic structure of the parenthetical constituent used in any sentence of Dimmesdale's narrative sentences loses the sentence its meaning and the designated effect which Hawthorne wants to create to his readers. So, the forms of the parenthetical constituents reinforce the meanings that Hawthorne wants to convey to his readers about Dimmesdale's character.

\section{References}

Alderson, C., \& Short, M. (1989). Reading literature. In M. Short (Ed), Reading, analysing, and teaching literature (pp. 72-119). London and New York: Longman.

Carter, R. (1989). Directions in the teaching and study of English stylistics. In M. Short (Ed.), Reading, analysing, and teaching literature (pp. 10-21). London and New York: Longman.

Crystal, D. (2003). A dictionary of linguistics \& phonetics (5th ed.). Oxford: Blackwell Publishing Ltd..

Fiedler, L. A. (1982). Love and death in the American novel. Harmondsworth: Penguin Books Ltd..

Gerber, J. (1944). Form and content in The Scarlet Letter. NEQ, 17, 25-55.

Guirad, P. (1971). Immance and transitivity of stylistic criteria. In S. Chatman (Ed.), Literary style: A symposium. New York: Oxford University Press. 
Halliday, M. A. K. (1973). Explorations in the functions of language. London: Edward Arnold. Hawthorne, N. (1992). The scarlet letter: A romance. London: David Campbell Publishers Ltd..

Huddleston, R., \& Pullum, G. (2005). A student's introduction to English grammar. United Kingdom: Cambridge University Press. Jespersen, O. ( 1925). Language: Its nature, development, and origin. London: George Allen \& Unwin Ltd..

Johnson, C. D. (1981). The productive tension of Hawthorne's art. Atlanta: The University of Atlanta Press.

Lall, R. (1970). Nathaniel Hawthorne, The Scarlet Letter: A critical study. New Delhi: Educational Publishers.

Leech, G. (1969). A linguistic guide to English poetry. London: Longman Group Limited.

Leech, G. (1970). This bread I break: Language interpretation. In D. C. Freeman (Ed.), Linguistics and literary style (pp. 119-128).

New York: Rinehart \& Winston.

Leech, G., \& Short, M. (1981). Style in fiction: A linguistic introduction to fictional prose. London: Longman Group Limited.

Leech, G., \& Svartivk, J. (1975). A communicative grammar of English. London: Longman Group UK Ltd..

Leech, G., Deuchar, M., \& Hoogenraad, R. (1982). English grammar for today: A new introduction. London: The Macmillan Press Ltd..

Loring, G. (1961). “Hawthorne’s Scarlet Letter” [1850] The Scarlet Letter: Text, sources, criticism. K. S. Lynn (Ed.). New York: Harcourt Brace \& world, Inc..

Mathews, J. W. (1957). Hawthorne and the chain of being. MLQ, 18, 282-294.

Mayhead, R. (1969). Understanding literature. Cambridge: Cambridge University Press.

McEnery, T., \& Wilson, A. (2001). Corpus linguistics: An introduction (2nd ed.). Edinburgh: Edinburgh University Press Ltd.. Mills, P. (1996). Writing in action. London: Routledge.

Nowottny, W. (1984). Poetic syntax. In N. Page (Ed.), The language of literature (pp. 71-74). London: Macmilian Press Ltd..

Quirk, R., \& Greenbaum, S. (1973). A university grammar of English. London: Longman Group Limited.

Robins, R. H. (1971). General linguistics: An introductory survey. London: Longman Group Limited.

Simpson, P. (2004). Stylistics. London: Routledge.

Thornborrow, J., \& Wareing, S. (1998). Patterns in language: An introduction to language and literary style. London: Routledge. Ullmann, S. (1973). Meaning and style. Oxford: Blackwell.

Waggoner, H. (1955). Hawthorne: Critical study. Cambridge: The Belknap Press of Harvard University.

Wardhaugh, R. (1977). Introduction to linguistics (2nd ed.). New York: McGraw-Hill Book Company.

Widdowson, H. G. (1975). Stylistics and the teaching of literature. London: Longman Group Ltd..

\section{Appendix 1: List of Symbols}

\section{Labels}

\begin{tabular}{ll}
\multicolumn{2}{l}{ Function Labels } \\
A & Adverbials \\
Aux & Auxiliary verb \\
C & Complement \\
Co & Object complement \\
Cs & Subject complement \\
H & Head \\
M & (Pre- or post-) modifier \\
Form & Labels \\
ACL & Adverbial clause \\
Aj & Adjective \\
AjP & Adjective phrase \\
Av & Adverb \\
AvP & Adverb phrase \\
CCL & Comparative clause \\
Cj & Subordinating or coordinating \\
& conjunction \\
CL & Clause \\
D & Determiner
\end{tabular}

\section{Function Labels}

C Complement

Co Object complement

Cs Subject complement

$\mathrm{H}$ Head

M (Pre- or post-) modifier

Form Labels

ACL Adverbial clause

Aj Adjective

AjP Adjective phrase

erb phrase

CCL Comparative clause

CL Clause 
$\begin{array}{ll}\text { E } & \text { Enumerator } \\ \text { Gp } & \text { Genitive Phrase } \\ \text { Ij } & \text { Interjection } \\ \text { MCL } & \text { Main clause }\end{array}$ -'s Genitive marker

SCL Subordinate clause

Se Sentence

VP Verb phrase

Wo Word

\section{Composite Labels}

CL, ACL, CCL, NCL, and RCL combine with i, ing, and en to form composite labels for non-finite clause types:

Cli Infinitive clause

Cling - ING clause

Clen - En clause

$\mathrm{V}$ and v combine with o, s, ed, i, ing, and en to form composite labels for finite and nonfinite verb forms:

Vo Present tense or base form

Vs Third person singular present tense form

Ved Past tense form

$\mathrm{Vi} \quad$ Infinitive

Ving -ING or present participle

Ven -En or past participle

\section{Special Labels}

The following symbols are used for subclasses of Aux and V:

$\begin{array}{rlll}\text { Aux: } \text { Mod } & \text { Modality } & \text { v: be } & \text { Primary verb to be } \\ \text { Pass } & \text { passive voice } & & \\ \text { Perf } & \text { Perfective aspect } & \text { do } & \text { “Dummy" verb do } \\ \text { Prog } & \text { Progressive aspect } & \text { hv } & \text { Primary verb to have } \\ & & \mathrm{m} & \text { Modal verb. }\end{array}$

The following particles are used as their own labels:

Not clause negation

To infinitive marker

\section{Bracketing}

[ ] around clauses

( ) around phrases

- $\quad$ separates word constituents

$<>\quad$ encloses two or more coordinates

\{ \} encloses an optional constituent

Form Labels are written as subscripts before the opening bracket or before the word: $N P(p n$ you!). While Function Labels VOC H

are written as superscripts before the opening bracket or before the word: ${ }^{(}$you!). In parsing, the function label is written

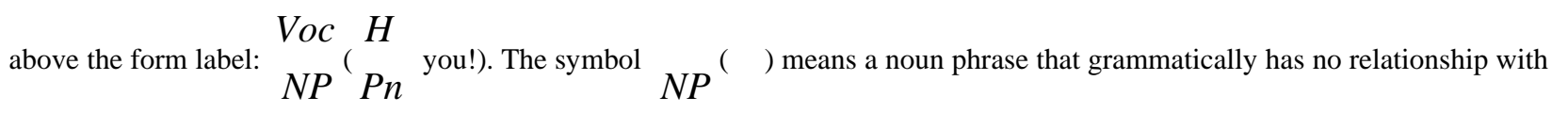
other components

\section{Notes Related to Citation Inside the Text}

Since the parsing is the author's and since its symbols, brackets, letters, etc., are added to Hawthorne's sentences, one did not write citation inside the text, i.e., after the parsed sentence. The parsed sentence, of course with all its symbols, does not exactly give the sentence which Hawthorne wrote in the novel. In an attempt to solve the problem of citing parsed sentences, one writes after each parsed sentence the chapter from which the sentence is taken as well as the number of the sentence that has a relationship to the number of the narrative sentences of the chapter, for example, Ch. 3. Se. 5. means narrative sentence five from chapter three. The citations of the 10 chapters of Hawthorne's The Scarlet Letter are as follow:

“The Prison-Door” (Hawthorne 49-50; Ch.1)

“The Market-Place” (Hawthorne 51-61; Ch.2) 
“The Recognition” (Hawthorne 62-72; Ch.3)

"The Leech and His Patient” (Hawthorne 133-143; Ch.10)

“The Interior of a Heart” (Hawthorne 144-151; Ch.11)

“The Minister’s Vigil” (Hawthorne 152-164; Ch.12)

“The Pastor and His Parishioner” (Hawthorne 196-206; Ch.17)

“A Flood of Sunshine” (Hawthorne 207-213; Ch.18)

“The Revelation of The Scarlet Letter” (Hawthorne 257-266; Ch.23)

“Conclusion” (Hawthorne 267-273; Ch.24)

\section{Appendix 2: Tables}

Table 3

Embedding in Dimmesdale's 274 Narrative Sentences

\begin{tabular}{|c|c|c|}
\hline Embedding (subordination) & Total number of cases & $\%$ \\
\hline Sentences that contain the process of embedding & 187 & \\
\hline Elements (s., o., and c.) that contain the process of embedding & 266 & \\
\hline Embedding at the end of the sentence & 176 & \\
\hline Embedding in $\mathrm{A}$ at the end of the sentence & 98 & 55.6818 \\
\hline Embedding in $\mathrm{O}$ at the end of the sentence & 34 & 19.3181 \\
\hline Embedding in $\mathrm{C}$ at the end of the sentence & 26 & 14.7727 \\
\hline Embedding in $\mathrm{S}$ at the end of the sentence & 18 & 10.2272 \\
\hline
\end{tabular}

Table 4

Stylistics Features of Arthur Dimmesdale's Narrative Sentences

\begin{tabular}{lr}
\hline Stylistics features & $f$. \\
\hline Fronting (subject, object, or complement) & 102 \\
Delaying (any structure) & 95 \\
Post modification of the head of the s., o., or c. (any structure) & 87 \\
Distancing structurally related items & 53 \\
Split constituent & 42 \\
Subject-verb inversion & 23 \\
Use of parenthetical constituent & 80 \\
Extraposition (of clausal subject) & 4 \\
Use of NP phrase in apposition & 4 \\
Embedding (the process itself) & 175 \\
Retaining the most complex structure to the end of the sentence & 121 \\
Vertical complexity (the process itself) & 175 \\
Emotive emphasis & 6 \\
Enclosure or confinement & 10 \\
Finite and non-finite clauses & $311 / 155$ \\
Periodic sentences & 70 \\
Postponement of post modifier & 7 \\
\hline
\end{tabular}

Table 5

Sentences' Types of Arthur Dimmesdale's Narrative Sentences

\begin{tabular}{lcc}
\hline Arthur Dimmesdale's narrative sentences & & \\
\hline Sentences types & Total & $\%$ \\
Complex sentences & 170 & 65.3846 \\
Compound sentences & 13 & 5 \\
Simple sentences & 69 & 26.5384 \\
p-less structure (sentence fragment) & 8 & 3.07692 \\
\hline Total & 260 & \\
\hline
\end{tabular}


Table 6

Fronting in Arthur Dimmesdale's Narrative Sentences

\begin{tabular}{lrr}
\hline Fronting & $f$. & $\%$ \\
\hline Fronting adverb & 95 & 93.1372 \\
Fronting object & 5 & 4.9019 \\
Fronting complement & 2 & 1.9607 \\
\hline Total & 102 & \\
\hline
\end{tabular}

Table 7

Embedding in Arthur Dimmesdale's Narrative Sentences

\begin{tabular}{lll}
\hline Embedding (subordination) & $f$. & $\%$ \\
\hline Sentences that contain the process of embedding & 175 & \\
Elements (s., o., and c.) that contain the process of embedding & 247 & 58.7878 \\
Embedding at the end of the sentence & 165 & 17.5757 \\
Embedding in A at the end of the sentence & 97 & 15.1515 \\
Embedding in O at the end of the sentence & 29 & 8.4848 \\
Embedding in C at the end of the sentence & 25 & 14 \\
Embedding in S at the end of the sentence
\end{tabular}

Table 8

Finite Clauses in Arthur Dimmesdale's Narrative Sentences

\begin{tabular}{llllll}
\hline ACL & NCL & CCL & RCL & PCL & Total \\
\hline 100 & 39 & 22 & 143 & 7 & 311 \\
\hline
\end{tabular}

Table 9

Non-finite Clauses in Arthur Dimmesdale's Narrative Sentences

\begin{tabular}{|c|c|c|c|c|c|c|c|c|c|c|c|c|}
\hline $\begin{array}{l}\text { Non-finite } \\
\text { clauses }\end{array}$ & $f$. & $\begin{array}{l}\text { Non-finite } \\
\text { clauses }\end{array}$ & $f$. & $\begin{array}{l}\text { Non-finite } \\
\text { clauses }\end{array}$ & $f$ & $\begin{array}{l}\text { Non-finite } \\
\text { clauses }\end{array}$ & $f$. & $\begin{array}{l}\text { Non-finite } \\
\text { clauses }\end{array}$ & $f$ & $\begin{array}{l}\text { Non-finite } \\
\text { clauses }\end{array}$ & $f$. & Total \\
\hline ACLing & 52 & NCLing & 6 & CCLing & 0 & RCLing & 16 & PCLing & 7 & CLing & 2 & \\
\hline ACLi & 16 & NCLi & 21 & CCLi & 0 & RCLi & 3 & PCLi & 0 & CLi & 5 & \\
\hline ACLen & 7 & NCLen & 3 & CCLen & 0 & RCLen & 17 & PCLen & 0 & & & \\
\hline Total & 75 & & 30 & & 0 & & 36 & & 7 & & 7 & 155 \\
\hline
\end{tabular}

Stylistics features of the narrative sentences that are related to the various explanations or the different interpretations of the token that has been witnessed on Dimmesdale's exposed breast = V.E.T.. These are 14 sentences which are combined (in this paper) with 260 narrative sentences that are related to Dimmesdale. So the total is 274 sentences.

Table 10

\section{Stylistics Features of V.E.T. Narrative Sentences}

\begin{tabular}{lr}
\hline Stylistics features & $f$. \\
\hline Fronting (subject, object, or complement) & 6 \\
Delaying (any structure) & 8 \\
Post modification of the head of the s., o., or c. (any structure) & 10 \\
Distancing structurally related items & 2 \\
Split constituent & 1 \\
Subject-verb inversion & 1 \\
Use of parenthetical constituent & 3 \\
Extraposition (of clausal subject) & 2 \\
Use of NP phrase in apposition & 1 \\
Embedding (the process itself) & 12 \\
Retaining the most complex structure to the end of the sentence & 10 \\
Vertical complexity (the process itself) & 12 \\
\hline
\end{tabular}


(Table 10 continued)

Stylistics features

Emotive emphasis

Enclosure or confinement

Finite and non-finite clauses

Periodic sentences

Postponement of post modifier

\begin{tabular}{l}
$f$. \\
0 \\
0 \\
$29 / 14$ \\
3 \\
0 \\
\hline
\end{tabular}

Table 11

Sentences' Types of V.E.T. Narrative Sentences

\begin{tabular}{lcl}
\hline V.E.T. narrative sentences & & \\
\hline Sentences types & Total & $\%$ \\
Complex sentences & 13 & 92.8571 \\
Compound sentences & 0 & 7.1428 \\
Simple sentences & 1 & \\
p-less structure (sentence fragment) & 0 & \\
\hline Total & 14 & \\
\hline
\end{tabular}

Table 12

Fronting in V.E.T. Narrative Sentences

\begin{tabular}{lll}
\hline Fronting & Total number of cases & $\%$ \\
\hline Fronting adverb & 6 & 100 \\
Fronting object & 0 & \\
Fronting complement & 0 & \\
\hline Total & 6 & \\
\hline
\end{tabular}

\section{Table 13}

Embedding in V.E.T. Narrative Sentences

\begin{tabular}{llr}
\hline Embedding (subordination) & $f$. & $\%$ \\
\hline Sentences that contain the process of embedding & 12 & \\
Elements (s., o., and c.) that contain the process of embedding & 19 & 9.0909 \\
Embedding at the end of the sentence & 11 & 45.4545 \\
Embedding in A at the end of the sentence & 1 & 9.0909 \\
Embedding in O at the end of the sentence & 5 & 36.3636 \\
Embedding in C at the end of the sentence & 1 & 4 \\
Embedding in S at the end of the sentence & 4 & \\
\hline
\end{tabular}

Table 14

Finite Clauses in V.E.T. Narrative Sentences

\begin{tabular}{llllll}
\hline ACL & NCL & CCL & RCL & PCL & Total \\
\hline 4 & 11 & 0 & 14 & 0 & 29 \\
\hline
\end{tabular}

Table 15

Non-finite Clauses in V.E.T. Narrative Sentences

\begin{tabular}{|c|c|c|c|c|c|c|c|c|c|c|c|c|}
\hline $\begin{array}{l}\text { Non-finite } \\
\text { clauses }\end{array}$ & $f$. & $\begin{array}{l}\text { Non-finite } \\
\text { clauses }\end{array}$ & $\bar{f}$. & $\begin{array}{l}\text { Non-finite } \\
\text { clauses }\end{array}$ & $f$ & $\begin{array}{l}\text { Non-finite } \\
\text { clauses }\end{array}$ & $f$. & $\begin{array}{l}\text { Non-finite } \\
\text { clauses }\end{array}$ & $f$ & $\begin{array}{l}\text { Non-finite } \\
\text { clauses }\end{array}$ & $f$ & Total \\
\hline ACLing & 1 & NCLing & 0 & CCLing & 0 & RCLing & 2 & PCLing & 2 & CLing & 0 & \\
\hline ACLi & 3 & NCLi & 1 & CCLi & 0 & $\mathrm{RCLi}$ & 0 & PCLi & 0 & CLi & 2 & \\
\hline ACLen & 0 & NCLen & 0 & CCLen & 0 & RCLen & 3 & PCLen & 0 & & & \\
\hline Total & 4 & & 1 & & 0 & & 5 & & 2 & & 2 & 14 \\
\hline
\end{tabular}

